\title{
NOTES
}

\section{Molecular Weight Distribution of Polyphenylene Sulfide by High Temperature Gel Permeation Chromatography}

\author{
Tatsuya HousAKI* and Kazuo SATOH \\ Polymer Research Laboratory, Idemitsu Petrochemical Co., Ltd., \\ 1-1 Anesaki-Kaigan, Ichihara, Chiba 299-01, Japan
}

(Received July 6, 1988)

\begin{abstract}
KEY WORDS Polyphenylene Sulfide (PPS) / Molecular Weight Distribution / Gel Permeation Chromatography (GPC) / Viscometric Detector /
\end{abstract}

Gel permeation chromatographic (GPC) determination of molecular weight distribution (MWD) of poly(phenylene sulfide) (PPS) must be carried out at high temperatures above at least $200^{\circ} \mathrm{C}$ because of its insolubility in the GPC carrier solvent below this temperature. However, conventional GPC detectors such as a differential refractometer (RI) or an ultraviolet/visible light (UV/Vis) absorption detector often did not function properly at such high temperatures. To avoid this difficulty, Stacy ${ }^{1}$ proposed use of a viscometric detector to determine the concentration $c$ of each fraction eluting at the elution volume $V e$. The idea is based on an assumption of infinite dilution approximation of $\eta_{\mathrm{sp}}=[\eta] c=K M^{a} c$ combined with the universal calibration concept of Benoit et al. ${ }^{2}$ who proposed that $[\eta] M=K M^{1+a}$ is a universal function (specific to the apparatus) of $V e$, where $\eta_{\mathrm{sp}}$ is the specific viscosity; $[\eta]$, the intrinsic viscosity; $M$, the molecular weight of the fraction; and $K$ and $a$ are the Mark-Houwink-Sakurada parameters of the particular polymer-solvent system to be studied. However, the Stacy method is not extremely accurate in determining $c$ especially of low $M$ (or large $V e$ ) fractions because of the low sensitivity of $\eta_{\mathrm{sp}}$ to $M$ in this region. Use of a flame ionization detector (FID) was suggested to monitor $c$ of the eluting fractions. ${ }^{3}$ This method, however, is also problematic because of an ambiguity resulting from the residual solvent effect due to the difficulty in removing from the quartz belt of FID thoroughly the usually less volatile carrier solvent for the high temperature GPC operation. ${ }^{4}$ If conventional $\mathrm{RI}$ and/or $\mathrm{UV} /$ Vis detectors can be operated above $200^{\circ} \mathrm{C}$, more accurate GPC data acquisition should be possible. To this end, we have modified GPC apparatus for high temperature operation and applied it to determine MWD of several commercial PPS samples. We compared the results of our modified GPC-UV/Vis method with those of the Stacy GPC-viscometric detector method. The purpose of this note is to report these results.

\section{EXPERIMENTAL}

A problem we encounter when operating $\mathrm{UV} /$ Vis absorption momitor of GPC at temperatures above $200^{\circ} \mathrm{C}$ is that the optical and electronic components often do not function properly. The cell component heated at $210^{\circ} \mathrm{C}$ must be apart from optical and electronic

* To whom all correspondence should be addressed. 


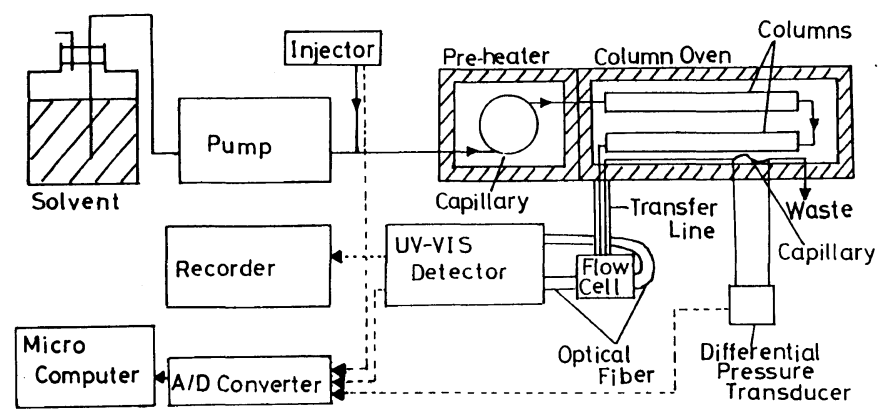

Figure 1. A schematic diagram of the instrument.

components. Optical fiber was used to transmit light from the optical component to electronic one. The cell with quartz windows was made of stainless steel, and the optical path length was $10 \mathrm{~mm}$. The high temperature GPC employed was modified as mentioned above of the Stacy type. ${ }^{1}$

A schematic diagram of the instrument is shown in Figure 1. This GPC system consists of a Spectraphysics SP8810 pump, a Rheodyne 7125 sample injector and a modified Soma Optics S-3702 UV/Vis absorption detector. Two Shodex AT80M/S columns from Showa Denko Co., Ltd. were used. The viscometric detector consists of a Solarton PD-3000 differential transducer $\left(0-15 \mathrm{~cm} \text { in } \mathrm{H}_{2} \mathrm{O}\right)^{1}$ and a capillary tube $(0.5 \mathrm{~mm}$ i.d. $\times 200 \mathrm{~mm})$. 1Chloronaphthalene (Tokyo Kasei Co., Ltd.) was used as the carrier solvent. ${ }^{1}$ The PPS samples examined are listed in Table I. To obtain homogeneous PPS slurry, we dissolved $20 \mathrm{mg}$ of PPS samples in $10 \mathrm{ml}$ of 1-chloronaphthalene under stiiring at $210^{\circ} \mathrm{C}$ for $10 \mathrm{~min}$ and quenched to room temperature. On each run $500 \mu \mathrm{l}$ of PPS slurry were injected at room temperature, and redissolved at $250^{\circ} \mathrm{C}$ through the capillary $(0.25 \mathrm{~mm}$ i.d. $\times 3 \mathrm{~m})$ in the preheater. The temperatures of the column oven, the transfer line, and the flow cell were regulated at $210^{\circ} \mathrm{C}$. A flow rate of $1.0 \mathrm{ml} \mathrm{min}^{-1}$ was adopted.

In order to determine the UV/Vis absorption peak of the phenyl sulfide group in 1-
Table I. Samples of commercial polyphenylene sulfide

\begin{tabular}{ccc}
\hline Sample & Intrinsic viscosity $\left(\mathrm{dl} \mathrm{g}^{-1}\right)^{\mathrm{a}}$ & Supplier \\
\hline A & 0.149 & Phillips \\
B & 0.228 & Kureha \\
C & 0.273 & Kureha \\
\hline
\end{tabular}

a Determined in 1-chloronaphthalene at $210^{\circ} \mathrm{C}$.

chloronaphthalene at $210^{\circ} \mathrm{C}$, diphenyl disulfide solution was examined and strong absorption was found at $356 \mathrm{~nm}$. To assure that this absorption resulted from the phenyl sulfide group, we also examined diphenyl thioether and PPS oligomer, and the strong absorption at $356 \mathrm{~nm}$ was observed in both cases.

From these results, the absorption at $356 \mathrm{~nm}$ was understood to result from the phenyl sulfide groups. For the calibration of the concentration and absorption intensity relation, five diphenyl disulfide samples with the concentration from $0.5 \mathrm{~g} \mathrm{l}^{-1}$ to $2.5 \mathrm{~g} \mathrm{l}^{-1}$ were measured. A good linear relation was observed as shown in Figure 2. This gives strong evidence for the the modified UV/Vis absorption detector installed in the present GPC system is useful as the concentration detector of PPS. The molecular weight dependence of the absorption intensity at $356 \mathrm{~nm}$ cannot be investigated because of lack of appropriate PPS standard samples. In order to obtain the MWD of PPS by the universal calibration method $^{2}$ using the Mark-Houwink- 


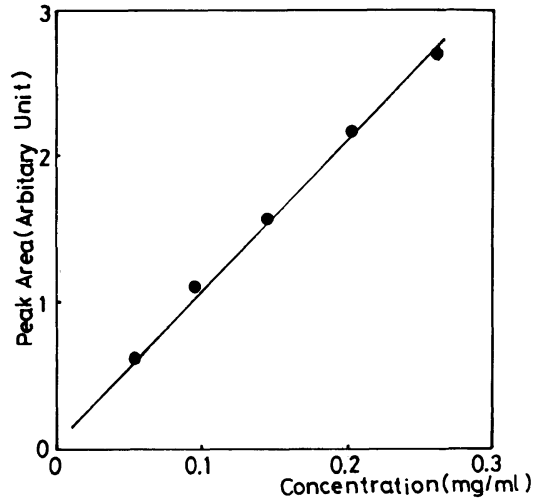

Figure 2. The relationship between the absorption peak area at $356 \mathrm{~nm}$ and the concentration of diphenyl disulfide in 1-chrolonaphthalene at $210^{\circ} \mathrm{C}$.

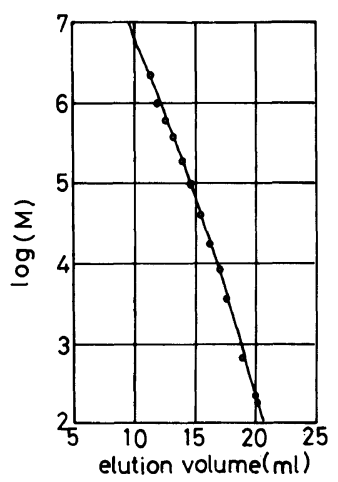

Figure 3. The molecular weight calibration curve of PPS.

Sakurada equation, ${ }^{1}$ monodisperse standard polystyrene $\left(M_{w}=20000\right.$, General Science Corporation) solution was examined. Unfortunately, however, the absorption from 1-chloronaphthalene was too strong to detect appropriate absorption of polystyrene. The viscometric detector was used to make a calibration curve of PPS by universal calibration method. ${ }^{4}$ We determined the time gap between the UV/Vis and viscometric detectors to be $6 \mathrm{~s}$ by carrying out measurement of PPS using only guard column. The molecular weight calibration curve of PPS used for the UV/Vis detector method was calculated after correcting the time gap. The result is shown in Figure 3. The data acquisition and treatment system

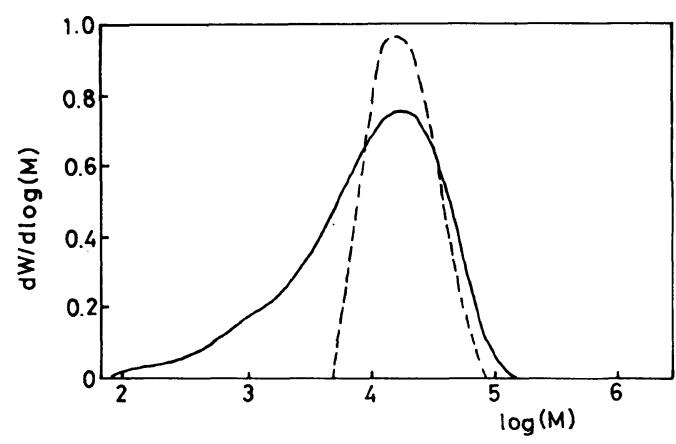

Figure 4. Molecular weight distribution of sample A: Solid curve, the UV/Vis absorption detector; dashed curve, the viscometric detector.

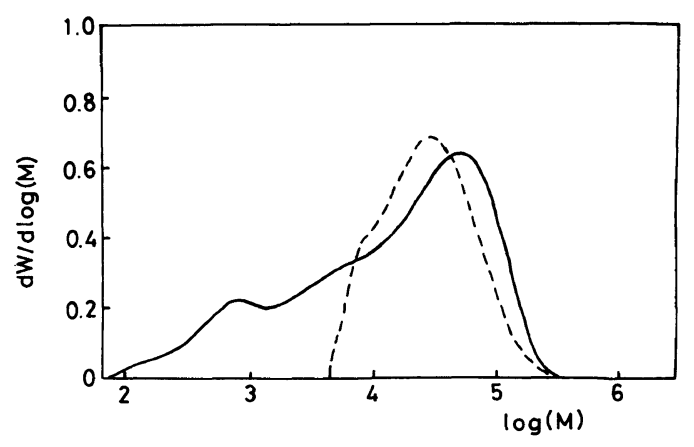

Figure 5. Molecular weight distribution of sample B: Solid curve, the UV/Vis absorption detector; dashed curve, the viscometric detector.

consists of an NEC PC9801VM computer (640 kbyte memory), an Neolog PCN-2198 analogto-digital converted board and an EPSON VP$85 \mathrm{~K}$ printer.

Injection signal, outputs of the UV/Vis detector and differential pressure transducer are all converted to digital outputs to calculate the chromatogram and stored in floppy disk. As soon as injection was completed the automatic acquisition and monitoring of the chromatogram was started. After the last run, calculations and graphic outputs are performed.

\section{RESULTS AND DISCUSSION}

Figures 4, 5, and 6, respectively, show the MWD curves determined for the samples A, B, and $\mathrm{C}$ listed in Table $\mathrm{I}$ by using the modified 
Table II. Molecular weight parameters of PPS samples

\begin{tabular}{ccccccc}
\hline Sample & $\bar{M}_{w} \times 10^{-3 \mathrm{a}}$ & $\bar{M}_{n} \times 10^{-3 \mathrm{a}}$ & $\bar{M}_{w} / \bar{M}_{n}^{\mathrm{a}}$ & $\bar{M}_{w} \times 10^{-3 \mathrm{~b}}$ & $\bar{M}_{n} \times 10^{-3 \mathrm{~b}}$ & $\bar{M}_{w} / \bar{M}_{n}{ }^{\mathrm{b}}$ \\
\hline A & 18.1 & 2.8 & 6.4 & 22.0 & 15.8 & 1.39 \\
B & 35.7 & 2.2 & 16.2 & 39.8 & 20.6 & 1.94 \\
C & 46.7 & 2.5 & 18.5 & 50.7 & 26.6 & 1.91 \\
\hline
\end{tabular}

a Obtained by the modified UV/Vis absorption detector method.

b Obtained by the Stacy viscometric detector method.

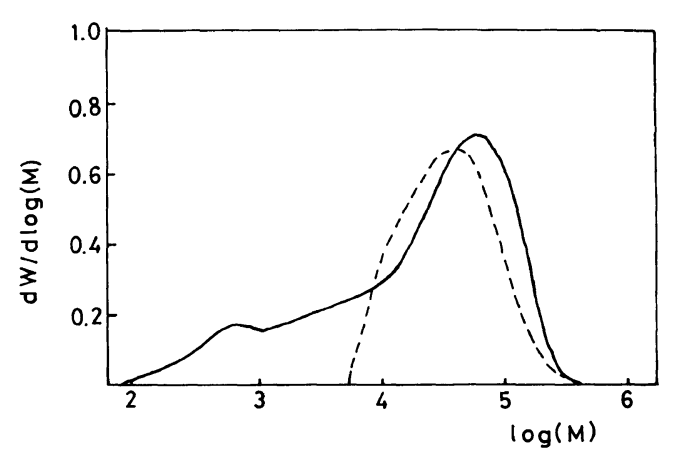

Figure 6. Molecular weight distribution of sample C: Solid curve, the UV/Vis absorption detector; dashed curve, the viscometric detector.

$\mathrm{UV} / \mathrm{Vis}$ detector and the Stacy viscometric detector systems. The present UV/Vis system yielded relatively broad MWD for all the samples in comparison with those of the viscometric detector system. Table II lists the number-average $\bar{M}_{n}$, the weight-average $\bar{M}_{w}$ molecular weights, and the polydispersity in$\operatorname{dex} \bar{M}_{w} / \bar{M}_{n}$ derived from these chromatograms. The polydispersity indices determined on the present $\mathrm{UV} / \mathrm{Vis}$ system are relatively large, while those obtained on the viscometric system are all less than 2 in accordance with the results reported for commercial PPS samples by Stacy. ${ }^{1}$ This large discrepancy is obviously due to the fact that the viscometric detector yielded much larger values of $\bar{M}_{n}$ than the modified UV/Vis detector. In case of the viscometric detector, the fractions with $M$ below several thousands could not be evaluated because of the lack of the sensitivity toward the low $M$ fractions. On the other hand, the modified UV/Vis system allowed us to carry out direct and accurate detection of $c$ of the fractions in the whole range of $M$. The apparently too narrow MWDs of the PPS samples from the viscometric detector system are probably an artifact, reflecting its low. sensitivity to the low $M$ fractions and the use of the indirect and approximate evaluation of $c$ of the fractions.

It is likely that the PPS samples in fact possess the rather broad MWD as detected with the present system.

\section{REFERENCES}

1. C. J. Stacy, J. Appl. Polym. Sci., 32, 3959 (1986).

2. Z. Grubisic, P. Rempp, and H. Benoit, J. Polym. Sci., B, 5, 753 (1967).

3. A. Kinugawa, Kobunshi Ronbunshu, 44, 139 (1987).

4. A. Kinugawa, The Toray Research Center News, 6-3, No. 2, 16 (July, 1987). 